\title{
Notícia: O Legado Científico de Angela Biaggio (1940-2003) para o Brasil
}

\author{
Cleonice Pereira dos Santos Camino ${ }^{1}$ \\ Universidade Federal da Paraíba
}

\section{News: Angela Biaggio's Scientific Legacy to Brazil}

Angela Biaggio apresenta uma notável produção acadêmica que evidencia seu envolvimento com a Psicologia do Desenvolvimento, e, de forma especial, com o Desenvolvimento Moral. Neste campo, ela foi pioneira e destacou-se, por mais de três décadas, como a mais importante pesquisadora do Brasil. A dedicação de Angela Biaggio pelo estudo da moral aparece claramente em seu artigo "Desenvolvimento Moral: Vinte anos de pesquisa no Brasil" (Biaggio, 1988) e em seu livro Lawrence Kohlberg: Ética e educação moral, onde, na página de agradecimentos, declara: "Este livro é fruto de mais de 30 anos de aprendizagem e pesquisa neste campo, desde meu doutoramento na Universidade de Wisconsin" (Biaggio, 2002). Na realidade, em toda a sua vida acadêmica, Angela Biaggio debruçou-se sobre questões morais.

Após o doutorado, Angela Biaggio procurou, através de estudos empíricos, verificar a aplicabilidade da teoria de Lawrence Kohlberg no Brasil. Tendo verificado a validade dos pressupostos kohlberguianos para a interpretação dos dados brasileiros, passou a utilizar, sistematicamente, a tipologia kohlberguiana em suas investigações sobre a moral.

Posteriormente, Angela Biaggio procurou aprofundar seu conhecimento sobre o desenvolvimento moral, investigando como ele poderia estar relacionado com dimensões psicológicas. Nesta linha de pesquisa, situam-se os estudos que verificaram: a influência do locus de controle no julgamento moral; a relação entre ansiedade e julgamento moral; e a relação entre personalidade e moralidade. Em outra linha de pesquisa, dentro do campo moral, Angela Biaggio procurou verificar a influência de fatores sociais sobre o desenvolvimento moral.

Além dessas investigações, nas quais Angela Biaggio não procurou intervir no curso espontâneo do desenvolvimento moral, encontram-se aquelas cujo objetivo central foi a promoção do desenvolvimento moral. Nesses trabalhos, uma das técnicas utilizadas foi a discussão de dilemas morais em grupo, técnica desenvolvida por Blatt e Kohlberg (1975) e amplamente utilizada nos Estados Unidos. Esta técnica, entretanto, apesar de se mostrar eficiente para promover a maturidade do pensamento moral, não é a mais eficiente para provocar, no comportamento moral, mudanças evolutivas compatíveis com as mudanças no pensamento. Como Angela Biaggio considerava altamente relevantes as mudanças comportamentais, procurou, através de um pós-doutorado com F.Clark Power - professor da Universidade Notre-Dame, Indiana - capacitar-se no uso da técnica de "comunidade

1 Endereço: Rua da Aurora, 201/908, 58043.270 Miramar, João Pessoa, PB, Brasil. E-mail: cleocamino@yahoo.com.br justa", técnica criada por Kohlberg na década de 70 com o objetivo de promover avanços no pensamento e na ação moral, de forma conjunta.

De volta ao Brasil, Angela Biaggio tentou aplicar uma adaptação do modelo de "comunidade justa" em uma escola de Porto Alegre. Infelizmente, mudanças ocorridas na direção da escola impossibilitaram-na de concluir esse trabalho de intervenção.

Mantendo vivo seu interesse pelo estudo do desenvolvimento moral, mas preocupada com questões éticas que afligem a humanidade, Angela Biaggio investigou outros valores, como a paz e o respeito pelo meio-ambiente, cuja dimensão social ultrapassa os limites do individual. De fato, diferentemente da justiça, valor central na teoria de Kohlberg, a paz e o respeito pelo meio-ambiente remetem, com facilidade, a uma visão global da sociedade. Desta forma, Angela Biaggio ampliou a sua contribuição para a construção de uma sociedade mais humana.

Além dos seus trabalhos empíricos sobre o desenvolvimento e a educação morais, ressaltam-se aqui algumas pesquisas de Angela Biaggio no campo da mensuração. Dentre outras, as suas pesquisas referentes à adaptação de medidas sobre a ansiedade e sobre a raiva, ambas em colaboração com Charles D. Spielberger, e as referentes à adaptação de medidas do julgamento moral, como as realizadas com o Moral Judgement Interview - MJI (medida subjetiva da moral, elaborada por Kolhlberg) e com o Sociomoral Reflexion Objectiv Measure - SROM (teste objetivo criado por John Gibbs). A adaptação desses dois últimos instrumentos foi de um valor inestimável para pesquisadores de diferentes universidades brasileiras.

Esse conjunto de pesquisas sobre o desenvolvimento moral, que se configura como um trabalho pioneiro de aprofundamento e de difusão de uma das teorias mais importantes do desenvolvimento moral nas últimas décadas, é um legado considerável que Angela Biaggio deixa para a área da Psicologia do Desenvolvimento no Brasil.

Mas não foi somente através de seu trabalho empírico que Angela Biaggio contribuiu para o avanço científico da psicologia no Brasil. Ela se dedicou a várias outras atividades, como ao ensino (Pontifícia Universidade Católica do Rio de Janeiro - PUC-RJ, Universidade de Brasília - UnB, Pontifícia Universidade Católica do Rio Grande do Sul - PUC-RS e Universidade Federal do Rio Grande do Sul - UFRGS), à orientação de dissertações de mestrado e teses de doutorado, à publicação de três livros (Psicologia do Desenvolvimento, 1975; Pesquisas em Psicologia do Desenvolvimento e da Personalidade, 1984; e, Lawrence Kohlberg: Ética e Educação Moral,2002), à publicação de inúmeros artigos em periódicos nacionais e estrangeiros. Além disso, ela participou 


\section{P. S. Camino}

de inúmeros encontros científicos nacionais e estrangeiros, foi membro de várias associações de Psicologia, nacionais e estrangeiras (presidente de honra da Sociedade Brasileira de Psicologia do Desenvolvimento, membro efetivo da American Psychological Association e presidente da Sociedade Interamericana de Psicologia - 1991 a 1993), participou, como coordenadora de área de Psicologia, no Conselho Nacional do Desenvolvimento Cientifico e Tecnológico (CNPq), na Coordenação do Aperfeiçoamento de Pessoal de Nível Superior (CAPES) e no comitê da Fundação de Amparo à Pesquisa do Estado do Rio Grande do Sul (FAPERGS).

Finalmente, Angela Biaggio, durante toda sua trajetória acadêmica, manteve forte intercâmbio com vários pesquisadores estrangeiros (Robert E. Grinder-orientador de seu doutorado-, F.Clark Power, Charles D. Spielberger, James Rest, Ann Higgins, Arne Vikan, John F. Snarey, Lutz Eckens Berger, Orlando Lourenço, Georg Lind e Larry Nucci) com os quais participou de debates em vários eventos científicos internacionais e com muitos dos quais desenvolveu projetos de pesquisas.

\section{Referências}

Biaggio, A. (1975). Psicologia do desenvolvimento. Petrópolis, R.J.: Editora Vozes.

Biaggio, A. (1984). Pesquisas em psicologia do desenvolvimento e da personalidade. Porto Alegre, RS: Editora da UFRGS.

Biaggio, A. (1988). Desenvolvimento moral: vinte anos de pesquisa no Brasil. Psicologia: Reflexão e Crítica, 1, 1-2, 60-69.

Biaggio, A. (2002). Lawrence Kohlberg: ética e educação moral. São Paulo: Moderna.

Blatt, M. \& Kohlberg, L. (1975). The effect of classroom moral discussion upon children's level of moral judgment. Journal of Moral Education, 4, 129-161.

Recebido em 14.07.2003 Aceito em 18.07.2003 